\title{
A Randomised Controlled Trial of the Effect of Low Fat Diet Advice on Dietary Response in Insulin Independent Diabetic Women
}

\author{
A. J. de Bont ${ }^{1}$, I. A. Baker ${ }^{1}$, A. S. St. Leger ${ }^{1}$, P. M. Sweetnam ${ }^{1}$, K. G. Wragg ${ }^{2}$, S. M. Stephens ${ }^{3}$ and T. M. Hayes ${ }^{2}$ \\ ${ }^{1}$ M. R. C. Epidemiology Unit, and ${ }^{2}$ Departments of Dietetics and Medicine, University Hospital of Wales, Cardiff, \\ and ${ }^{3}$ Department of Dietetics, Royal Gwent Hospital, Newport, Wales, UK
}

\begin{abstract}
Summary. Type 2 (insulin independent) diabetic women were randomly allocated to receive advice for low fat diets or low carbohydrate diets. By $24 \mathrm{~h}$ weighed dietary intakes before and after a mean interval of six months, patients in the low fat group had reduced their fat intake from $41 \%$ to $31 \%$ of total energy, while carbohydrate percentage of total energy intake increased from $38 \%$ to $46 \%$. Percentage energy intake from fat and carbohydrate in the control group remained unchanged. Body weight fell in both groups, especially for patients in the low fat group who were obese (weight $/$ height $^{2} \geqslant 28 \mathrm{~kg} / \mathrm{m}^{2}$ ). Mean plasma glucose, $\mathrm{HbA}_{1}$, and triglycerides were unchanged. Mean plasma total cholesterol fell significantly in the low fat group compared with the controls $(p<0.001)$, but there was no significant difference in the small reduction of high density lipoprotein cholesterol observed in both groups. Thus, adherence to low fat diets occurred without deterioration of diabetes and with benefit for weight and total cholesterol.
\end{abstract}

Key words: Type 2 (insulin independent) diabetic women, low fat diets, diabetic control, cardiovascular risk factors.

Diabetics in Western countries have an increased cardiovascular mortality and morbidity compared with the non-diabetic population [1,2]. Diabetes has been demonstrated to be an independent risk indicator of mortality from coronary heart disease, and the blood lipid levels of diabetic patients exceed those found in non-diabetics [2-4]. Evidence from the Seven Countries study [5] supports the association of the fat composition of diets, the plasma cholesterol and the risk for coronary heart disease. There has therefore been interest in the effect of low fat diets on the management of diabetic patients in contrast to conventional low carbohydrate, high fat diets [6,7]. This study measures the response of patients to advice for low fat diets through weighed food intakes, diabetic control and certain risk indicators for cardiovascular diseases, namely body weight and plasma lipids.

\section{Subjects and Methods}

One hundred and seventy Type 2 (insulin independent) diabetic women, aged 35-64 years and free of other diseases, were identified from patients attending hospital clinics. Of these patients 148 agreed to participate in the study. They were randomly allocated to receive advice for low fat or low carbohydrate diets from experienced hospital dietitians. No specific dietary regimes were used. Instead the dietitians reviewed the current diets of the patients: for the low fat group advice was given which attempted to reduce the contribution of fat towards $30 \%$ of the prescribed total energy intake. This concentrated on reducing dairy products and fat from meat, and substituting margarines in order to improve the saturated-polyunsaturated fat balance. To maintain the required total energy intake the proportion of carbohydrates in these diets was increased. Patients in the low carbohydrate group acted as controls against which the effect of the advice to the low fat diet group would be measured. The patients in the low carbohydrate group also had their current diets reviewed and advice was given to encourage a carbohydrate intake not exceeding $40 \%$ of the prescribed total energy intake. During the period of study all patients received three home visits from a single nutritionist who encouraged continued adaptation of diets towards the low fat or the low carbohydrate dietary targets.

Dietary response was measured by one-day food intakes before dietary advice was given and again at the end of the study, using the 'weighed inventory method' [8]. Weighing scales (Salter No. 50T) were supplied to each patient who was asked to weigh and record every food item to the nearest $1 / 8 \mathrm{oz}(3.54 \mathrm{~g})$. If the complete food intake could not be measured at home, weighing elsewhere was encouraged or a description of unweighed items was obtained and estimations made of quantities involved. Dietary records were checked for completeness with the patient by the nutritionist. Weighed inventory records at the end of the study were obtained by two trained field workers who were blind to the group allocation of 
Table 1. Entry characteristics of patients who completed the study

\begin{tabular}{lllll}
\hline Characteristics & \multicolumn{2}{l}{$\begin{array}{l}\text { Low fat } \\
\text { group }(n=71)\end{array}$} & \multicolumn{2}{l}{$\begin{array}{l}\text { Low CHO } \\
\text { group }(n=65)\end{array}$} \\
\hline Age (years) & 56 & $(7)$ & 54 & $(8)$ \\
Body weight (kg) & 72 & $(15)$ & 73 & $(16)$ \\
Duration of diabetes (years) & 6.9 & $(5.9)$ & 6.9 & $(5.3)$ \\
Fasting plasma glucose (mmol/1) & 9.1 & $(3.0)$ & 9.7 & $(3.4)$ \\
Fasting plasma HbA $(\%)$ & 10.0 & $(2.3)$ & 10.1 & $(2.4)$ \\
Duration of study (days) & 170 & $(29)$ & 164 & $(27)$ \\
Current smokers & \multicolumn{2}{c}{$44 \%$} & \multicolumn{2}{c}{$37 \%$} \\
Diabetic management: & \multicolumn{2}{c}{$3 \%$} \\
$\quad$ Diet only & \multicolumn{2}{c}{$37 \%$} & \multicolumn{2}{c}{$34 \%$} \\
Diet + oral hypoglycaemic drugs & $62 \%$ & \multicolumn{2}{c}{$65 \%$} \\
Diet + insulin & \multicolumn{2}{c}{$1 \%$} & \multicolumn{2}{c}{$2 \%$} \\
\hline
\end{tabular}

Results expressed as mean value (SD) or as percentage of total group

the patients. These visits were arranged for the same day of the week as the weighed record on entry. Visits were unannounced in order to improve the validity of the records. Total energy and nutrient intake were estimated using 'McCance and Widdowson's food tables' [9] supplemented by more recent information from British and foreign food industries.

Weight and height measurements and fasting blood samples were obtained before dietary advice was given and at the end of the study. Body weight in the fasting state was measured by beam balance to the nearest $0.1 \mathrm{~kg}$. Standing height was measured to the nearest $0.1 \mathrm{~cm}$. Plasma glucose was measured by the method of Trinder [10] and haemoglobin $\mathrm{A}_{1}\left(\mathrm{Hb}_{1}\right)$ by a standard commercial method ('Quik-sep' Isolaboratories, Akron, Ohio). Plasma cholesterol was determined according to a modification of the method of Richardson et al. [11]. High density lipoprotein (HDL) cholesterol was measured by the same method after precipitation of very low density lipoproteins (VLDL) and low density lipoproteins (LDL) according to the method of Burstein and Samaille [12]. Plasma triglycerides were measured by a standard enzymatic method ('Precilip' Lot No. 764, Boehringer, Mannheim). Whenever appropriate, pooled plasma samples with known values were included in each batch of measurements. When the observed values of these measurements were outside accepted intervals, the whole batch was reanalysed. Since HDL cholesterol values of stored human plasma can vary over time [13], a new pooled sample was prepared for the estimations of HDL cholesterol at the end of the study. Coefficients of variation for unidentified split blood samples at the baseline were $2.5 \%$ for plasma glucose, $3.3 \%$ for total plasma cholesterol, $7.7 \%$ for $\mathrm{HDL}$ cholesterol, $4.4 \%$ for triglycerides and $2.1 \%$ for $\mathrm{HbA}_{1}$.

Results are presented as mean values and standard deviations (SD). The indices of outcome are the changes in diabetic control, weight and plasma lipids between entry to and end of the study. The effect of the low fat dietary advice has been measured by comparing these changes with those observed in the low carbohydrate advice group. Statistical significance has been assessed by Student's ' $t$ ' test.

\section{Results}

Of the 148 patients who entered the study, $137(93 \%)$ were re-assessed 6 months later. Amongst the 11 patients who were unavailable, six had been withdrawn by their physicians, four withdrew themselves and one patient died. Another patient had a total cholesterol value which at entry to the study was close to the upper limit of laboratory measurement and which at the end of the study exceeded that limit. Her results were excluded from the analysis. Entry characteristics of the 136 patients who completed the study are shown in Table 1. There were no important differences in these characteristics between the two groups. After selection for the study, but before receiving dietary advice, two patients were prescribed insulin: their results have been included.

\section{Dietary Response}

Dietary response in the two groups is shown in Table 2. The patients who were given advice for low fat diets showed a marked fall in the percentage of energy derived from total fats and a rise in the percentage derived from total carbohydrates. The percentages of energy derived from total fats and carbohydrate were essentially unchanged in the low carbohydrate $(\mathrm{CHO})$ control group. The differences in response between the low fat group and the low $\mathrm{CHO}$ group for both nutrients were highly statistically significant $(p<0.001)$. The final percentage of total energy derived from fat in the low fat group is close to the target set at the beginning of the study.

The decrease in fat consumption in the experimental group was accompanied by a change in the balance of the component fats. Saturated and monounsaturated fats both decreased markedly while the percentage energy derived from polyunsaturated fats rose. The change in all three components differed significantly $(p<0.001)$ from the changes observed in the low $\mathrm{CHO}$ group.

The increase in carbohydrate consumption in the experimental group arose largely through increases in polysaccharides. The small increase in oligosaccharides was not significantly different from the corresponding change in the low $\mathrm{CHO}$ group.

Dietary cholesterol fell by $105 \mathrm{mg} / 1000 \mathrm{kcal}$ in the low fat group while it rose by $24 \mathrm{mg} / 1000 \mathrm{kcal}$ in the low $\mathrm{CHO}$ group. This difference was highly significant $(p<0.001)$. Dietary fibre rose in both groups but the difference in the increase between the two groups was not significant. Total energy fell in both groups but again the difference between the groups was not significant.

Analysis of changes in the intake of specific food items from the beginning to the end of the study revealed that patients in the low fat group had reduced their intake of butter, whole milk, cheese and eggs. More soft margarine of high polyunsaturated fat content was taken. For the same patients bread, especially 
Table 2. Changes in total energy intake, percentage of energy intake by nutrient and dietary cholesterol and fibre intakes between entry to and end of study

\begin{tabular}{|c|c|c|c|c|c|c|c|c|c|}
\hline \multirow[b]{3}{*}{ Total energy (kcal) } & \multicolumn{4}{|c|}{ Low fat group $(n=71)$} & \multirow{3}{*}{$\frac{p^{2}}{\mathrm{NS}}$} & \multicolumn{4}{|c|}{ Low CHO group $(n=65)$} \\
\hline & \multirow{2}{*}{$\begin{array}{l}\text { Mean on } \\
\text { entry }\end{array}$} & \multirow{2}{*}{$\begin{array}{l}\begin{array}{l}\text { Mean at } \\
\text { end }\end{array} \\
1197\end{array}$} & \multicolumn{2}{|c|}{ Mean (SD) change } & & \multirow{2}{*}{$\begin{array}{l}\begin{array}{l}\text { Mean on } \\
\text { entry }\end{array} \\
1460\end{array}$} & \multirow{2}{*}{$\begin{array}{l}\text { Mean at } \\
\text { end }\end{array}$} & \multicolumn{2}{|c|}{ Mean (SD) change } \\
\hline & & & -98 & $(369)$ & & & & -120 & $(485)$ \\
\hline Total proteins $(\%)$ & 20.3 & 22.7 & 2.4 & $(7.0)$ & NS & 18.2 & 19.9 & 1.7 & $(5.9)$ \\
\hline Total fats $(\%)$ & 41.2 & 31.1 & -10.1 & $(10.8)$ & $<0.001$ & 42.8 & 41.8 & -1.0 & $(10.5)$ \\
\hline Total carbohydrates (\%) & 37.8 & 45.7 & 7.9 & $(9.5)$ & $<0.001$ & 38.1 & 38.0 & -0.1 & $(10.9)$ \\
\hline Alcohol $(\%)$ & 0.5 & 0.3 & -0.2 & (1.6) & NS & 0.6 & 0.1 & -0.4 & $(2.6)$ \\
\hline Saturated fats (\%) & 20.0 & 12.0 & -8.1 & (5.8) & $<0.001$ & 21.0 & 19.9 & -1.1 & $(5.7)$ \\
\hline Mono-unsaturated fats (\%) & 16.0 & 11.3 & -4.7 & (4.7) & $<0.001$ & 16.7 & 16.6 & -0.2 & $(4.7)$ \\
\hline Polyunsaturated fats $(\%)$ & 4.8 & 7.4 & 2.6 & (4.6) & $<0.001$ & 4.6 & 4.8 & 0.3 & $(2.7)$ \\
\hline Oligosaccharides (\%) & 11.6 & 13.5 & 1.9 & $(6.0)$ & NS & 11.4 & 11.5 & 0.1 & $(5.6)$ \\
\hline Polysaccharides (\%) & 26.2 & 32.1 & 6.0 & (7.5) & $<0.001$ & 26.6 & 26.4 & -0.2 & $(9.2)$ \\
\hline \multicolumn{10}{|l|}{ Dietary cholesterol } \\
\hline$(\mathrm{mg} / 1000 \mathrm{kcal})$ & 287 & 182 & -105 & $(163)$ & $<0.001$ & 237 & 261 & 24 & $(172)$ \\
\hline \multicolumn{10}{|l|}{ Dietary fibre } \\
\hline$(\mathrm{g} / 1000 \mathrm{kcal})$ & 11.4 & 14.7 & 3.4 & (7.1) & NS & 10.4 & 12.0 & 1.6 & $(6.1)$ \\
\hline
\end{tabular}

a Statistical significance for comparison of change in the low fat group with the change in the low CHO group

$\mathrm{NS}=$ not significant

Table 3. Change in body weight between entry to and end of study. Subjects subdivided according as they were obese or not on entry to the study

\begin{tabular}{lllllll}
\hline & No. of subjects & \multicolumn{2}{l}{ Weight $(\mathrm{kg})$} & & & \\
\cline { 5 - 7 } & & Mean on entry & Mean at end & Mean (SD) change & $p^{\mathrm{a}}$ \\
\hline Obese patients; & 34 & 84.2 & 81.5 & -2.7 & $(3.6)$ & $<0.05$ \\
$\quad$ Low fat group & 35 & 84.8 & 83.9 & -0.9 & $(3.5)$ & \\
$\quad$ Low CHO group & 36 & 60.1 & 59.7 & -0.4 & $(2.8)$ & NS \\
$\quad$ Non-obese patients; & 29 & 59.0 & 59.1 & +0.1 & $(2.0)$ & \\
$\quad$ Low fat group & Low CHO group & & & & & \\
\hline
\end{tabular}

${ }^{a}$ Statistical significance for comparison of change in weight in the low fat group with the change in the low CHO group $\mathrm{NS}=$ not significant

Subjects defined as obese if weight $/$ height $\mathrm{t}^{2}\left(\mathrm{~kg} / \mathrm{m}^{2}\right) \geqslant 28.0$

wholemeal, potatoes and skimmed milk consumption increased. Changes in these food items in the intake of patients receiving low carbohydrate advice were less marked or absent. For this group there was a fall in the consumption of various confectioneries, but a small increase in consumption of bread. There was little change in the type of meat, fruit and legumes consumed by either group of patients.

\section{Diabetic Control}

Patients in the low fat group and the low carbohydrate group had mean fasting plasma glucose levels of 9.1 and $9.7 \mathrm{mmol} / 1$ respectively on entry to the study. At final assessment mean levels had decreased by $0.3 \mathrm{mmol} / 1$ in the low fat group and by $0.5 \mathrm{mmol} / \mathrm{l}$ in the low carbohydrate group. The difference in fall of mean plasma glucose between the groups was not statistically significant. Diabetic control was also assessed by measurements of fasting plasma $\mathrm{HbA}_{1}$. On entry the mean levels were $10.0 \%$ and $10.1 \%$ for the low fat and the low carbohydrate groups respectively. These levels fell by $0.7 \%$ in the low fat group and by $0.6 \%$ in the low carbohydrate group. The difference in the fall of mean plasma $\mathrm{HbA}_{1}$ levels between the groups was again not significant. Thus there was essentially no change in diabetic control in association with the observed changes in diet of the low fat group. During the study four patients in the low fat group had their dosage of oral hypoglycaemic drugs increased and for another six patients the dosage of these drugs was decreased. Ten patients in the low carbohydrate group received increased dosage of oral hypoglycaemic drugs and another three patients were commenced on insulin therapy. 
Table 4. Changes in plasma total cholesterol, HDL cholesterol and total triglycerides between entry to and end of study

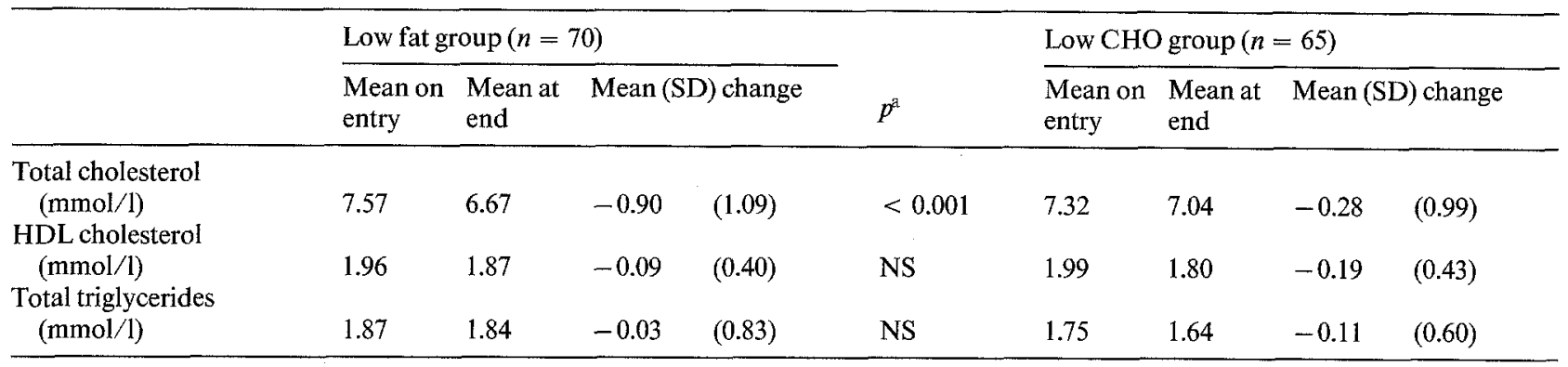

a Statistical significance for comparison of change in lipid in the low fat group with the change in the low CHO group NS $=$ not significant

\section{Body Weight and Plasma Lipids}

Changes in body weight (Table 3 ) were studied by dividing patients in both groups into those who were obese (weight $/$ height $^{2} \geqslant 28 \mathrm{~kg} / \mathrm{m}^{2}$ ) and those who were not on entry to the study. The cut-off point of $28 \mathrm{~kg} / \mathrm{m}^{2}$ corresponds on average with $35 \%$ body fat $[14,15]$. Obese patients on a low fat diet showed a significant decrease in weight $(2.7 \mathrm{~kg})$ compared with obese patients in the control group $(0.9 \mathrm{~kg}, p<0.05)$. For those patients classified as non-obese, weight changes were small in both groups and the difference between the groups was not statistically significant.

Details of changes in plasma total cholesterol, HDL cholesterol and total triglycerides are given in Table 4. Total cholesterol decreased in patients in both groups, the fall of $0.90 \mathrm{mmol} / 1$ in the low fat group being significantly greater $(p<0.001)$, than the fall of $0.28 \mathrm{mmol} / 1$ in the low carbohydrate group. Mean HDL cholesterol and total triglycerides decreased slightly in both groups: in neither case was the difference between the groups statistically significant.

\section{Discussion}

The study was designed to measure the effect of giving practical advice for a change of food intake from the conventional low carbohydrate diet to a diet with a fat content of around $30 \%$ of its total energy. Women diabetics were chosen who were insulin independent. In terms of their initial fasting plasma glucose and $\mathrm{HbA}_{1}$, there was considerable variation in diabetic control (Table 1). The purpose of the low carbohydrate diet group was to control for any secular changes in diet, for changes in diabetic management and for the additional attention given to the low fat diet group. These arrangements for control were facilitated by the fact that most patients were infrequent attenders at hospital clinics and in particular had not seen the dietitians for some years.
The reduction in the percentage of total energy intake derived from fats shows clearly that the low fat dietary advice was generally effective. Support for this assertion can be gained also by relating the change in plasma total cholesterol to the change expected from modification of the fat content of the diet according to the equation derived from the metabolic experiments of Keys et al. [16]. According to the modifications of saturated and polyunsaturated fats and dietary cholesterol observed in both groups of patients during the study, the mean decrease in plasma cholesterol in the low fat group was predicted to be $0.52 \mathrm{mmol} / 1$. This approximates closely to the observed decrease of $0.62 \mathrm{mmol} / 1$ for plasma cholesterol in the low fat group, when the change in plasma cholesterol in the low carbohydrate group is taken into account.

Obese patients in both groups lost weight, but more so in the low fat group. Changes in total energy intake were small and similar for both groups. When total energy intake was analysed for obese and nonobese patients separately, there was no differential change in total energy intake which would explain the reduction in body weight amongst the obese. No obvious change in energy output was observed. The mechanism for this reduction in weight remains unclear.

There were no significant changes in HDL cholesterol levels. These findings are of interest when considering the inverse associations of body weight and HDL cholesterol in cross-sectional studies [17], although the weight changes in this study were small. Hulley et al. also reported the absence of significant change in HDL cholesterol following weight loss [18]. With the greater reduction of plasma total cholesterol in the low fat group a small increase in the ratio of HDL cholesterol to total cholesterol occurred in comparison to the changes in the low carbohydrate group. Carbohydrate induced hypertriglyceridaemia was not observed [19]. 
The dietary response to low fat dietary advice in this population of diabetics seems to be encouraging given the absence of deterioration in diabetic control and the improvement of some risk indicators for cardiovascular diseases.

Acknowlegements. Dr. H. J. Lloyd, Royal Gwent Hospital, Newpott made it possible to include his patients in this study. We thank. Miss E. Reynolds and Mrs. S. Williams for their skilful technical assistance in laboratory analyses. Dr. D. Philpotts, Biochemistry Department, Frenchay Hospital, Bristol kindly analysed samples for plasma glucose concentrations. Miss J. Marr, Department of Clinical Epidemiology, Royal Free Hospital, London was extremely helpful in lending us her weighing scales for the dietary survey. Mrs. J. Habgood (dietitian) and Miss J. Fawcett gave dietary advice to the patients and we thank them for their involvement. Mrs. J. Hughes and Mrs. M. Jones took care of the 'weighed inventory' records at evaluation. We thank them for their dedicated help.

The late Mr. A. de Bont was supported by a Royal Society fellowship as part of the European Science Exchange Programme of the Royal Society London and the 'Netherlands Organization for the Advancement of Pure Research' (Z. W. O.)

\section{References}

1. Garcia MJ, McNamara PM, Gorton T, Kannell WB (1974) Morbidity and mortality in diabetics in the Framingham population. Sixteen year follow-up study. Diabetes 23 : 105-111

2. Heyden S, Heiss G, Bartell AG, Hames CG (1980) Sex differences in coronary mortality amongst diabetics in Evan's County Georgia. J Chron Dis 33: 265-273

3. Gordon T, Castelli WP, Hjortland MC, Kannell WB, Dawber TR (1977) Diabetes, blood lipids, and the role of obesity in coronary heart disease risk for women. Ann Intern Med 87 : 393-397

4. Jarrett RJ, Keen H (eds) (1980) Complications and diabetes. Edward Arnold, London, pp 179-203

5. Keys A (1980) 'Seven countries'. A multivariate analysis of death and coronary heart disease. Harvard University Press, Cambridge Massachusetts, pp 248-262

6. Stone DB, Connor WE (1963) The prolonged effects of a low cholesterol, high carbohydrate diet upon the serum lipids in diabetic patients. Diabetes 12: 127-132
7. Hockaday TDR, Hockaday JM, Mann JI, Turner RC (1978) Prospective comparison of modified-fat - high-carbohydrate dietary advice in the treatment of diabetes. One year follow-up study. Br J Nutr 39: 357-362

8. Marr JW (1971) Individual dietary surveys: purposes and methods World Rev Nutr Diet 13: 105-164

9. Paul AA, Southgate DAT (eds) (1978) 'McCance and Widdowson's the composition of foods', 4th edn. HMSO, London

10. Trinder P (1969) Determination of blood glucose using an oxidase-peroxidase system with a non-carcinogenic chromogen. $J$ Clin Pathol 22: 158-161

11. Richardson RW, Setchell KDR, Woodman DD (1971) An improved procedure for the estimation of serum cholesterol. Clin Chim Acta 31: 403-407

12. Burstein M, Samaille J (1960) Sur un dosage rapide de cholesterol lié aux $\alpha$-et aux $\beta$-lipoproteines du serum. Clin Chim Acta 5:609

13. Bachorik PS, Walker R, Brownell KD, Stunkard AJ, Kwiterovich PO (1980) Determination of high density lipoprotein-cholesterol in stored human plasma. J Lipid Res 21:608-616

14. Keys A, Fidanza F, Karvonen MJ (1972) Indices of relative weight and obesity. J Chronic Dis 25:329-343

15. James WPT (ed) (1976) Research on obesity. A report of the DHSS/MRC group. HMSO, London, $\mathrm{p} 9$

16. Keys A, Anderson JT, Grande F (1965) Serum cholesterol response to changes in the diet. IV. Particular saturated fatty acids in the diet. Metabolism 14: 776-787

17. Gordon T, Castelli WP, Hjortland MC, Kannell WB, Dawber TR (1977) High density lipoprotein as a protective factor against coronary heart disease. Am J Med 62: 707-714

18. Hulley SB, Cohen R, Widdowson G (1977) Plasma high-density lipoprotein cholesterol levels. Influence of risk factor intervention. J Am Med Assoc 238: 2269-2271

19. Ginsberg H, Olefsky JM, Kimmerling G, Crapo P, Reaven GM (1976) Induction of hypertriglyceridaemia by a low-fat diet. J Clin Endocrinol Metab 42: 729-735

Received: 24 January 1981

and in revised form: 3 July 1981

Mr. P.M. Sweetnam

MRC Epidemiology Unit

4 Richmond Road

Cardiff CF2 3 AS, UK 